\title{
Research on the Forecast of Urban Underground Space Demand
}

\author{
Lin Xin ${ }^{1, *}$, Du Zhehua $^{2}$ \\ ${ }^{1}$ Hubei Province Engineering Consulting Co., LTD., 430071 Wuhan, China \\ ${ }^{2}$ Wuhan Second Ship Design and Research Institute, 430205 Wuhan, China
}

\begin{abstract}
Forecasting the capacity demand of underground space is the difficulty and a heat point in urban planning and urban underground space development. Through the survey data of Shanghai underground space capacity in 2006 and 2008, this paper conducts an empirical study on forecasting the capacity demand of underground space using thespatial regression model as the classical model by applying tools of STATA, SPSS and ArcGIS. The study indicates that the scale of underground space development and use is in a significant positive relationship with the population density and GDP per capita, but is not relevant with the price of real estate. The characteristics are apparently different in the underground space development and use in Shanghai between the central and the rural area. The underground space development in Shanghai is at the stage of rapid promotion, and will keep increasing at a high speed. The paper reveals the development law of Shanghai underground space development and the method of forecasting the capacity of underground space so as to provide theoretical analysis tool for development of underground space in Shanghai and other cities.
\end{abstract}

\section{Introduction}

Urban underground space is an important field of urban space expansion in China, which has accommodated a large number of development and construction activities. Relying on the construction of rail transit system, the development and utilization of underground space in large and medium-sized cities in developed coastal areas in China are in full swing.

Urban underground space reserves refers to the city from the surface to the core of all the space. It is infinite in theory, but urban underground space resources suitable for development and utilization are very limited in a certain period. Subjective and objective factors, such as engineering technology, engineering geology and hydrogeology, to a certain extent, limit the scope and depth of underground space development and utilization. At the same time, the development and utilization of underground space is irreversible. Sterling et al. believe that once underground space is developed, it cannot be restored or demolished, but can only be backfilled and discarded. The construction, operation and maintenance costs of developing and utilizing underground space are several times higher than the cost of ground space [1]. Therefore, in a certain period of time, the scale of urban underground space that can be developed and utilized is restricted by its own development law. Therefore, it is of great significance to grasp the law of underground space development and utilization scale, master the method of predicting underground space development scale, and rationally develop and utilize urban underground space for sustainable urban development.

This study uses urban macroeconomic indicators as predictive variables to explore the scale of underground space development suitable for the level of urban economic development. This study takes Shanghai as a case to explore the endogenous motivation of the scale of underground space development and utilization.

\section{Existing forecasting methods}

At present, there are three ways to express the concept of urban underground space scale.

- Firstly, the function scale of each sub-system is calculated respectively, and then the predicted values of each system are added up to obtain the total demand scale of urban underground space [2].

- The per capita underground space demand is predicted, and then the total urban underground space demand is obtained by multiplying it with predicted population $[3,4]$.

- The underground space demand per unit land area is predicted and multiplied by the total urban land area to get the total urban underground space demand $[5,6]$.

There is currently no unified method for predicting the scale of underground space development and utilization. According to the different guiding ideas of predicting the scale of underground space, the existing four forecasting methods are divided into two categories.

The first category is to regard underground space as a supplement to above-ground space. Under the guidance of this idea, the demand of underground space can be obtained by predicting the total demand of city and subtracting the supply of aboveground space. Therefore, the problem of predicting the demand for underground space is transformed into the problem of predicting the

\footnotetext{
*Corresponding author: 754726516@qq.com
} 
total demand for future urban construction scale. Chen L.D. and Chen Z.L. respectively used two methods to forecast the city's total demand. Chen L.D. takes the prediction of future population as the basis [7], while Chen Z.L. takes eco-city as the final state of future city [8]. These two methods have obvious disadvantages, that is, it is very difficult to predict the future state of urban development. Because cities are complex systems, it is even more difficult to predict during period of drastic changes in China's urban population and urban land use.

The second category is that urban underground space is an important part of urban space and plays an important role in the sustainable development of cities. This method promotes the interactive use of urban space. Under the guidance of this idea, the prediction of the ratio of underground space to aboveground space becomes the basis of the scale prediction of urban underground space $[9,10]$. This method relies too much on subjective judgment, so the results are not entirely convincing. Different people may come to different judgment results for the same city due to their differences in case selection, experience reserve, preferences and other aspects.

\section{Demand forecasting model}

\subsection{Influential factor framework}

Through the review and analysis of existing literature, the factors that affect the development and utilization of urban underground space can be summarized, which can be divided into two aspects: internal system and external system. The internal system refers to the inherent characteristics of underground space, such as constant temperature, constant humidity, airtight, thermal insulation, energy saving and other natural properties, which promotes the use of underground space in environmental protection, urban landscape, noise control and other elements. The external system includes socioeconomic system and natural environment system. Socioeconomic system includes economic development, real estate market, commercial competition, land scarcity, population growth, urban sprawl, traffic congestion and other factors. Natural environment system includes topographic conditions, climatic conditions and other factors.

\subsection{Variable selection and research hypothesis}

\subsubsection{Variable selection}

The selection of variables follows three principles: the principle of extensiveness, the principle of representativeness, and the principle of quantification. Therefore, urban economic and social system is selected as the first level of variables. The economic and social system generally contains three elements: per capita GDP, population density and real estate price, covering three important aspects of a city's economy, population and land. GDP per capita is an indicator to measure the level of urban economic development. Population density is an index to measure the degree of land congestion. Real estate prices indirectly reflect the price of land, that is, the scarcity of land.

\subsubsection{Research hypothesis}

Population growth has caused pressure on urban environment and land use, so it is necessary to make full use of underground space to alleviate the above urban problems. Therefore, the four factors of population growth, urban problems, improvement of space utilization efficiency and environmental protection can be reflected indirectly through the factors of urban population density. When economy has developed to a certain stage, residents have put forward higher demand for pleasant spaces. Therefore, the level of economic development and the creation of pleasant spaces can be combined into urban GDP per capita. Land prices reflect the scarcity of urban land. Therefore, per capita GDP, population density and real estate price are selected as factors influencing the development scale of underground space in this study.

\subsection{Sample data acquisition}

The total development data of underground space of 19 districts (counties) in Shanghai in 2006 and 2008 were obtained through Shanghai underground space survey. Economic data and population data can be referred to Shanghai Statistical Yearbooks in 2006 and 2008. Real estate price data is more difficult to collect. Through literature search, second-hand housing data is used for analysis. The data on the scale of development and utilization of underground space is limited to the part that is normally used, excluding the area of underground space for civil air defense. Underground space development and utilization area includes not only actual use area, but also structural area.

\subsection{Model assumption}

\subsubsection{Spatial autocorrelation problem}

Since 19 districts (counties) in Shanghai are close to each other in geographical space, statistical variables may be affected by spatial autocorrelation, and cannot reflect the real relationship among the variables. Therefore, in order to quantify the spatial correlation of descriptive variables, ArcGIS spatial statistics function is used for analysis. It is assumed that the space is homogenous, that is, there is only one trend that covers the whole region, so as to determine the regional distribution characteristics of each variable in Shanghai. The result is shown in Table 1. In addition to the underground space development density in 2008, all the other variables have global spatial correlation and meet the reliability requirements.

Table1. Global statistics Moran I analysis

\begin{tabular}{|c|c|c|c|c|}
\hline Variable & $\begin{array}{c}\text { Moran } \\
\text { I }\end{array}$ & $\begin{array}{c}\text { Z- } \\
\text { score }\end{array}$ & $\begin{array}{c}\text { P- } \\
\text { value }\end{array}$ & $\begin{array}{c}\text { Spatial } \\
\text { correlation }\end{array}$ \\
\hline DUUS2006 & 0.52 & 7.20 & 0.00 & Agglomeration \\
\hline PD2006 & 0.62 & 8.48 & 0.00 & Agglomeration \\
\hline
\end{tabular}




\begin{tabular}{|c|c|c|c|c|}
\hline GDP2006 & 0.39 & 5.62 & 0.00 & Agglomeration \\
\hline REP2006 & 0.36 & 5.28 & 0.00 & Agglomeration \\
\hline DUUS2008 & -0.16 & -1.36 & 0.17 & Random \\
\hline PD2008 & 0.61 & 8.45 & 0.00 & Agglomeration \\
\hline GDP2008 & 0.15 & 2.58 & 0.01 & Agglomeration \\
\hline REP2008 & 0.41 & 5.85 & 0.00 & Agglomeration \\
\hline
\end{tabular}

In local spatial autocorrelation analysis, Z-score reflects the agglomeration and dispersion of research elements. When Z-score is greater than 2.58 standard deviation, the spatial agglomeration of elements occurs at 99\% level. When Z-score is between 1.96 and 2.58 standard deviations, the spatial agglomeration of elements occurs at $95 \%$ level. When Z-score is between 1.65 and 1.96 standard deviations, the spatial agglomeration of elements occurs at $95 \%$ level. When Z-score is between 1.65 and 1.65 standard deviation, the element space is discrete.

\subsubsection{Correlation problem of time series data}

Due to the possible temporal correlation between 2006 data and 2008 data, dummy variable $D_{2}$ is introduced to represent the impact of different time period. If variable is 2008 data, then $D_{2}=1$. If variable is 2008 data, then $D_{2}=$ 0.

\subsubsection{Regression model assumption}

According to the autocorrelation analysis of spatial data, models can be divided into two categories: spatial correlation and time series autocorrelation regression model, and spatial difference and time series autocorrelation regression model.

- Spatial correlation and time series autocorrelation regression model assumption.

There are three types of spatial regression models: spatial autoregressive model, spatial lag model and spatial error model. Spatial lag model indicates that the explained variables of studied region are not only related to the explained variables of local region, but also related to the explained variables of adjacent region. In other words, underground space development and utilization density of a certain district (county) in Shanghai is not only related to the economic and social development level of the district (county), but also has a certain relationship with underground space development and utilization of its neighboring districts (county). This situation is consistent with the basic hypothesis of this research. In this study, the first-order spatial lag model (Equation 1) was used as the regression basic hypothesis model.

$$
\begin{gathered}
Y=\alpha w Y+\beta X+\varepsilon \\
D U U S=\beta_{0}+\beta_{1} \times w \times D D U S+\beta_{2} \times P D \\
+\beta_{3} \times G P D+\beta_{4} \times R E P+\beta_{5} \times D_{2}
\end{gathered}
$$

- Regression model assumption related to spatial differences and time series.

$$
\begin{gathered}
D U U S=\beta_{0}+\beta_{1} \times P D+\beta_{2} \times R E P \\
+\beta_{3} \times G P D+\beta_{4} \times D_{1}+\beta_{5} \times D_{2}
\end{gathered}
$$

The formula for the central city area in 2008 is as follows.

$$
D U U S=\beta_{0}+\beta_{1} \times P D+\beta_{2} \times R E P+\beta_{3} \times G P D+\beta_{4}+\beta_{5}
$$

The formula for the central city area in 2006 is as follows.

$$
D U U S=\beta_{0}+\beta_{1} \times P D+\beta_{2} \times R E P+\beta_{3} \times G P D+\beta_{4}
$$

The formula for the suburbs in 2008 is as follows.

$$
D U U S=\beta_{0}+\beta_{1} \times P D+\beta_{2} \times R E P+\beta_{3} \times G P D+\beta_{5}
$$

The formula for the suburbs in 2006 is as follows.

$$
D U U S=\beta_{0}+\beta_{1} \times P D+\beta_{2} \times R E P+\beta_{3} \times G P D
$$

DUUS - Underground space development density $\left(10000 \mathrm{~m}^{2} / \mathrm{km}^{2}\right)$

$P D$ - Population density (10000 people $\left./ \mathrm{km}^{2}\right)$ $/ \mathrm{m}^{2}$ )

$R E P$ - Average annual real estate price (10000 yuan

$G D P$ - Real gross domestic product per capita(10000 yuan/person)

$w$ - Spatial weight coefficient of study area

$\beta_{0}, \beta_{1}, \beta_{2}, \beta_{3}, \beta_{4}, \beta_{5}$ - Undetermined coefficient $\varepsilon-$ Residual

\subsection{Model building}

Correlation analysis of factor and regression analysis of explanatory model are carried out in SPSS and Stata software.

\subsubsection{Correlation analysis and partial correlation analysis}

There is a significant positive correlation between underground space development density and population density. GDP and real estate prices are weakly correlated. The remaining four partial correlation analyses all show weak correlation. This can lead to a preliminary conclusion that the density of underground space development is related to population density, and GDP is related to real estate price.

\subsubsection{Regression analysis}

- Regression model analysis of spatial correlation and time series correlation

In the case of multiple linear regression, in order to eliminate the influence of non-linearity, Box-Cox transformation is first performed for corresponding variables.

$$
\text { DUUS }=[\text { DUUS (original) }]^{0.24}
$$

All explanatory variables are substituted into the equation as variables for regression analysis. The explanatory variables $P D, G D P$, and $D_{1}$ all pass the hypothesis test at $95 \%$ level, and $R_{2}=0.95$. The model has high explanatory power. Regression equation is as follows. $D_{U U S} S^{0.24}=3.55+0.36 w \times D U U S+2.45 \times P D+1.1 \times G P D(9)$

The domain of equation is the range of selected variables. Population density (PD) ranges from 0.05 to 43400 people $/ \mathrm{km}^{2}$. Per capita GDP is 0.48 to 25600 yuan per person. DUUS is the development density of underground space, the unit is $10000 \mathrm{~m}^{2} / \mathrm{km}^{2}$. 
- Regression model analysis of spatial difference and time series correlation.

In Stata software, multiple linear regression is used to perform regression analysis on the transformed model. It is found that time dummy variables $D_{2}$ and $R E P$ failed hypothesis test. Finally, the explanatory variables that meet the requirements of hypothesis testing are obtained as follows: $P D, G D P$ and $D_{l}$. Regression equation is shown in Equation 10.

$D U U S^{0.24}=3.60+2.59 \times P D+1.49 \times G P D+2.52 \times D_{1}(10)$

Regression equation of central city is as follows.

$D_{U U S} S^{0.24}=6.12+2.59 \times P D+1.49 \times G P D$

Regression equation of suburbs is as follows.

DUUS $^{0.24}=3.60+2.59 \times P D+1.49 \times G P D$

\section{Conclusion}

Currently, there is no uniform method for predicting the scale of urban underground space. The scale of urban underground space can not be predicted scientifically by relying too much on the prediction of future and subjective judgment. This research proposes a model prediction method based on measured data. Taking Shanghai as an example, a mathematical model is established to predict the scale of underground space demand in Shanghai in the future based on the data of urban macro-economic development. The study introduces the method of selecting explanatory variables, and proposes three explanatory variables: population density, per capita GDP and real estate price. The relationship between explanatory variables and underground space development density is excavated, and the analysis method of regression model is used. It is of certain reference significance to the subsequent research on the scale demand prediction of the development and utilization of underground space in other cities.

\section{References}

1. R.L. Sterling, S.R. Nelson, M. Jaffe, University of Minnesota Underground Space Center, (1982)

2. N. Bobylev, Tunnelling and Underground Space Technology, 25, 495 (2010)

3. A. Nordmark, Tunnelling and Underground Space Technology, 17, 163 (2002)

4. P. Belanger, Tunnelling and Underground Space Technology, 22, 272 (2007)

5. Z.L. Chen, D.J. Guo, Planners, 23(10), 9 (2007)

6. G.Q. Xu, S. Zheng, L.L. Hu, Urban Planning Forum, S1, 62 (2008)

7. L.D.Chen, Tongji University Press, (1997)

8. Z.L. CHEN, Y.B. Wang, Southeast University Press, (2005)

9. H.W. Paker, Tunnelling and Underground Space Technology, 11, 133 (1996)

10. D. Ahrens, Tunnelling and Underground Space Technology, 12, 505 (1997) 